\title{
ISOTOPE EFFECT FOR CATION DIFFUSION IN COO
}

\section{by}

N. L. Peterson and W. K. Chen

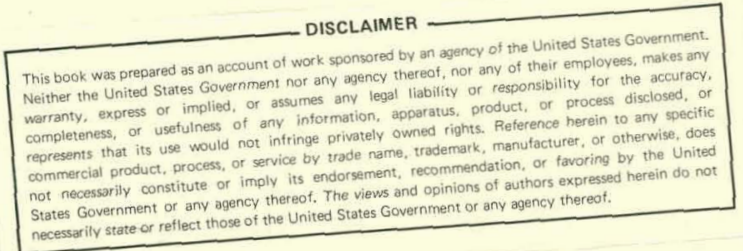

Prepared for

Third Europhysical Topical Conference

on

Lattice Defects in Ionic Crystals

Canterbury, England

September 17-21, 1979

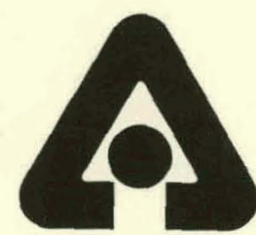

U Of C-AUA-USDOE 


\section{DISCLAIMER}

This report was prepared as an account of work sponsored by an agency of the United States Government. Neither the United States Government nor any agency Thereof, nor any of their employees, makes any warranty, express or implied, or assumes any legal liability or responsibility for the accuracy, completeness, or usefulness of any information, apparatus, product, or process disclosed, or represents that its use would not infringe privately owned rights. Reference herein to any specific commercial product, process, or service by trade name, trademark, manufacturer, or otherwise does not necessarily constitute or imply its endorsement, recommendation, or favoring by the United States Government or any agency thereof. The views and opinions of authors expressed herein do not necessarily state or reflect those of the United States Government or any agency thereof. 


\section{DISCLAIMER}

Portions of this document may be illegible in electronic image products. Images are produced from the best available original document. 
The facilities of Argonne National Laboratory are owned by the United States Government. Under the terms of a contract (W-31-109-Eng-38) among the U. S. Department of Energy, Argonne Universities Association and The University of Chicago, the University employs the staff and operates the Laboratory in accordance with policies and programs formulated, approved and reviewed by the Association.

\section{MEMBERS OF ARGONNE UNIVERSITIES ASSOCIATION}

The University of Arizona

Carnegie-Mellon University

Case Western Reserve University

The University of Chicago

University of Cincinnati

Illinois Institute of Technology

University of Illinois

Indiana University

The University of Iowa

Iowa State University
The University of Kansas

Kansas State University

Loyola University of Chicago

Marquette University

The University of Michigan

Michigan State University

University of Minnesota

University of Missouri

Northwestern University

University of Notre Dame
The Ohio State University

Ohio University

The Pennsylvania State University

Purdue University

Saint Louis University

Southern Illinois University

The University of Texas al Austin

Washington University

Wayne State University

The University of Wisconsin-Madison

NOTICE

This report was prepared as an account of work sponsored by an agency of the United States Government. Neither the United States nor any agency thereof, nor any of their employees, makes any warranty, expressed or implied, or assumes any legal liability or responsibility for any third party's use or the results of surh use of any information, apparatus, product or process disclosed in this report, or represents that its use by such third party would not infringe privately owned rights. Mention of commercial products, their manufacturers, or their suppliers in this publication does not imply or connote appiuval ur disapproval of the product by Argonne National Laboratory or the United States Government. 
Isotope Effect for Cation Diffusion in CoO*

N. L. Peterson and W. K. Chen

Argonne National Laboratory

Argonne, IL 60439

\section{Abstract \\ The simultaneous diffusion of ${ }^{55} \mathrm{Co}$ and ${ }^{60}$ Co has been measured} In $\mathrm{CoO}$ as a function of equilibrium oxygen pressure in the range $10^{-9}<\mathrm{p}_{\mathrm{O}_{2}}<1$ atm at $1200^{\circ} \mathrm{C}$. The slope of the $\log \mathrm{D}_{\mathrm{Co}}^{*}$ vs $\log \mathrm{p}_{\mathrm{O}_{2}}$ plot changes from a value of about $1 / 4$ at high $\mathrm{p}_{\mathrm{O}_{2}}$ to about $1 / 5$ at low $\mathrm{P}_{2}$ in agreement with the extensive measurements of Dieckmann. The isotope effect is independent of $\mathrm{p}_{\mathrm{O}_{2}}$, which suggest.s that diffusion by defect clusters, interstitial co ions and impurityinduced defects is not important in the present measurements. Conductivity, diffusion, stoichiometry, and isotope-effect results are consistent with diffusion by neutral, singly charged, and doubly charged vacancies; the relative contributions from the various vacancies varies with $\mathrm{P}_{2} \cdot$

*Work supported by the U.S. Department of Energy. 
1. Introduction. - Cobalt monoxide is an off-stoichiometric, $\mathrm{NaCl}-$ structured oxide exhibiting p-type semiconduction at high temperatures with oxygen pressures near $1 \mathrm{~atm}$. The extensive measurements of the deviation from stolchiometry $\delta$, as a function of $\mathrm{P}_{\mathrm{O}_{2}}[1-6]$ show an excess of oxygen ions relative to cobalt ions. The rapid cation tracer diffusion [1,7-9] relative to the anion tracer diffusion [10] $\left(\mathrm{D}_{\mathrm{Co}}^{*} / \mathrm{D}_{\mathrm{O}}^{*} \sim 5 \times 10^{4}\right.$ at $\left.1200^{\circ} \mathrm{C}\right)$ strongly suggests that the excess oxygen Ions are accomodated by the formation of cation vacancies rather than anion intersititals.

It is apparent from the above that the principal point defects to be considered in $\mathrm{CoO}$ are cation vacancies and electron holes. Various charges are possible for the cation vacancies. The formation of neutral vacancies can be expressed as follows:

$$
1 / 2 \quad o_{2}(g)=v_{C o}^{x}+o_{\ell}
$$

Singly charged vacancies can be formed by the dissociation of neutral vacancies:

$$
\mathrm{v}_{\mathrm{Co}}^{\mathrm{x}}=\mathrm{v}_{\mathrm{Co}}^{\prime}+\mathrm{h}
$$

Further dissociation of electron holes yields doubly charged vacancies:

$$
\mathrm{v}_{\mathrm{Co}}^{\prime}=\mathrm{v}_{\mathrm{Co}}^{\prime \prime}+\mathrm{h}
$$

If only one type of cation vacancy is present in CoO, and the defect concentration is sufficiently low that defect-defect interactions can be neglected, then the application of the low of mass action to eqs. (1) - (3) allows one to relate the defect concentration to the oxygen partial pressure:

$$
\begin{aligned}
& {\left[\mathrm{v}_{\mathrm{Co}}^{\mathrm{x}}\right] \propto\left(\mathrm{p}_{\mathrm{O}_{2}}\right)^{1 / 2}} \\
& {\left[\mathrm{v}_{\mathrm{Co}}^{\prime}\right] \propto\left(\mathrm{p}_{\mathrm{O}_{2}}\right)^{1 / 4}} \\
& {\left[\mathrm{v}_{\mathrm{Co}}^{\prime \prime}\right] \propto\left(\mathrm{p}_{\mathrm{O}_{2}}\right)^{1 / 6} .}
\end{aligned}
$$


The bracketed quantities are the fraction of point-defect species per mole of cation lattice sites. If the mobility of the various cationvacancy types is the same and independent of $\mathrm{p}_{\mathrm{O}_{2}}$, then a measurement of the cation tracer diffusivity as a function of $\mathrm{P}_{\mathrm{O}_{2}}$ may be related to the deviation from stoichiometry $\delta$ and provide a determination of the dominant vacancy type from its $\mathrm{p}_{\mathrm{O}_{2}}$ dependence.

Most measurements of $\delta[1-3,5,6]$, electrical conductivity $[3,11-13]$ and cation tracer diffusion $[1,7.8]$ are concentrated at high $\because \mathrm{p}_{\mathrm{O}_{2}}$ values and may be fitted to eq. (5), indicating a dominance of singly charged cation vacancies. Several measurements of $\delta[4]$, electrical conductivity $[2,5,14]$, and cation tracer diffusion [9] cover a large range of $\mathrm{p}_{\mathrm{O}_{2}}$. These measurements show a curved plot vs $\log \mathrm{P}_{\mathrm{O}_{2}}$, indicating that more than one type of defect is present in CoO.

Dieckmann [9] has made an extensive analysis of the literature data on the $\mathrm{P}_{\mathrm{O}_{2}}$ dependence of $\delta$ and electrical conductivity, and of his own results on cation tracer diffusion. In addition to neutral, singly charged and doubly charged vacancies [eqs. (1) - (3)], he also included Frenkel point-defect equilibrium and Schottky point-defect equilibrium in his analysis. Dieckmann was able to obtain an acceptable fit of this simple five-defect "ideal solution" model to the existing data. He concludes that the concentrations of cobalt interstitials and oxygen vacancies are negligible; the dominant defects are vacancies on the cation sublattice and electron holes, and the vacancies can be formally treated as neutral, singly, or doubly charged. The curvature in the plots of $\log D_{C o}^{*}$ vs $\log \mathrm{P}_{2}$ (and similar plots for $\delta$ and electrical conductivity as a function of $\mathrm{P}_{\mathrm{O}_{2}}$ ) can be quantitatively interpreted in terms of a change in relative contributions of differently charged vacancies with varying $\mathrm{p}_{\mathrm{O}_{2}}$ as shown by Dieckulann [9]. Other possible Interpretations of the data include (a) impurity-induced (extrinsic) defects at low $\mathrm{P}_{\mathrm{O}_{2}}$ and (b) defect clustering at high $\mathrm{p}_{\mathrm{O}_{2}}$ 
One measurement that may distinguish between the possible interpretations of the data is the $\mathrm{P}_{\mathrm{O}_{2}}$ dependence of the correlations factor f for cation diffusion: (a) If the interpretation of Dieckmann is correct, $f$ for cation diffusion should be independent of $\mathrm{p}_{\mathrm{O}_{2}}$ (if the vacancies do not interact with each other). (b) If there is a small concentration of trivalent impurity ions in the $\mathrm{CoO}$, these lons would introduce extrinsic vacancies that would make a larger relative contribution at $10 \mathrm{w} \mathrm{P}_{\mathrm{O}_{2}}$ than at high $\mathrm{p}_{2}$. Cobalt diffusion by bound impurity-vacaricy pairs will occur with a much smaller $f$ than for cation diffusion by free vacancies. Thus, $f$ for cation diffusion would decrease, with decreasing $\mathrm{P}_{\mathrm{O}_{2}}$. (c) Defectclustering effects may be important at high $\mathrm{p}_{\mathrm{O}_{2}}$ where the total vacancy concentration may reach $1 \%$. As an example, calculations by Catlow et al. [15] for Mno show that at $\delta=10^{-4}$ (corresponding to low $\mathrm{p}_{\mathrm{O}_{2}}$ in CoO), all the defects are iscolated vacancies; at $\delta=10^{-2}$ (corresponding to high $\mathrm{P}_{\mathrm{O}_{2}}$ in $\left.\mathrm{CoO}\right), 87 \%$ of the vacancies are in clusters of four vacancies or larger. If the calculations for MnO are at all relevant for CoO, defect clustering may be expected to play a major role in cobalt monoxide. Measurements on $\mathrm{Fe}_{1-\delta} \mathrm{O}$ suggest that $\mathrm{f}$ decreases when defect clustering becomes important [16]. Thus one expects $f$ to decrease with increasing $\mathrm{P}_{\mathrm{O}_{2}}$ if defect clustering is important in CoO.

In this paper we present results on the $\mathrm{p}_{\mathrm{O}_{2}}$ dependence of $\mathrm{f}$ using isotope-effect techniques in order to select the appropriate interpretation of the diffusion and conductivity outlined in the above paragraph. Values of $\mathrm{D}_{\mathrm{Co}}^{*}$ as a function of $\mathrm{P}_{\mathrm{O}_{2}}$ are a by-product of the isotope-effect experiments and may be used to check the recent values of Dieckmann.

For tracer diffusion in solids, information concerning the value of $f$ may be obtained from the relative diffusion rates of two isotopes of the same element [17]. The general expression for the 1sotopic mass effect in diffusion is [18] 


$$
E \equiv\left(\frac{D_{\alpha}}{D_{\beta}}-1\right) /\left[\left(\frac{m_{\beta}}{m_{\alpha}}\right)^{1 / 2}-1\right]=f \Delta K,
$$

where the subscripts $\alpha$ and $\beta$ pertain to isotopes with masses $m_{\alpha}$ and $\mathrm{m}_{\beta}$, respectively. The term $\Delta \mathrm{K}$ is the fraction of the total translational kinetic energy at the saddle point, associated with motion in the direction of the diffusional jump, that belongs to the jumping atom. The measured value of $E$ and the allowed values of $f$ and $\Delta K$ may permit an unambiguous determination of the diffusion mechanism. Although $\Delta \mathrm{K}$ may have different values for different mechanisms, $\Delta \mathrm{K}$ is thought to be independent of $\mathrm{P}_{\mathrm{O}_{2}}$ for a given mechanism at constant temperature.

2. Experimental Results and Discussion - The tracer-sectioning technique was employed for the measurements of ${ }^{60} \mathrm{Co}$ diffusion in CoO single crystals. The various values of $\mathrm{P}_{2}$ were established by a $\mathrm{CO}_{2}-\mathrm{CO}$ or $\mathrm{Ar}-\mathrm{O}_{2}$ gas mixture or pure $\mathrm{O}_{2}$ flowing through the furnace. The samples were diffusion annealed at $1200^{\circ} \mathrm{C}$ and at the same $\mathrm{p}_{\mathrm{O}_{2}}$ as was used for an extensive preanneal. For the isotope-effect measurements, ${ }^{55}$ co and ${ }^{60}$ Co were diffused simultaneously in the CoO crystals. The ratio of the specific activities of the two Isotopes, necessary for the determination of $\left(D_{\alpha} / D_{\beta}\right)-1$, was determined at various positions in the sample to within $0.1 \%$ by a half-life separation of the $\gamma$ activity of ${ }^{55} \mathrm{Co}$ and ${ }^{60} \mathrm{Co}$. Details of the experimental technique may be found in Ref. 7 .

Diffusion and isotope-effect measurements were made at six values of $\mathrm{p}_{\mathrm{O}_{2}}$ at $1200^{\circ} \mathrm{C}$. The values of $\log \mathrm{D}_{\mathrm{Co}}^{*}$ are plotted vs $\log \mathrm{p}_{\mathrm{O}_{2}}$ in Fig. 1 ; the earlier results of Dieckmann [9] and the present authors [7] are also shown. The solid line is a result of Dieckmann's empirical fit of the defect model to the nonstoichiometric data, the electrical conductivity data and his diffusion data [9]. The present results are in acceptable agreement with Diecknenn's empirical model. Lines with a slope of $1 / 4$ and $1 / 6$, corresponding to diffusion by singly ionized and doubly lonized vacancies [eqs (5) and (6)], respectively, are also shown. 
The values of $f \Delta \mathrm{K}$ are also plotted vs $\log \mathrm{p}_{\mathrm{O}_{2}}$ in Fig. 1 . A value of $\mathrm{f} \Delta \mathrm{K}=0.58$ (within $3 \%$ ), independent of temperature and oxygen partial pressure, is probably the best value for CoO. This value of $f \Delta \mathrm{K}$ is consistent with diffusion by noninteracting vacancies and $\Delta K=0.75$ as previously discussed [7].

of the four possible causes of curvature in the $\log \mathrm{D}_{\mathrm{Co}}^{*}$ vs $\log \mathrm{P}_{\mathrm{O}_{2}}$ plot discussed in the Introduction, only the change in relative contribution of differently charged vacancies with varying $\mathrm{p}_{\mathrm{O}_{2}}$ is consistent with the present, $\mathrm{P}_{\mathrm{O}_{2}}$-independent value of $\mathrm{f} \Delta \mathrm{K}$. The other possible causes of curvature are expected to produce a $\mathrm{P}_{\mathrm{O}_{2}}$-dependent value of $\mathrm{f} \Delta \mathrm{K}$ that would be observable within the present experimental error. As an example, if impurity-induced (extrinsic) defects or interstitials at low $\mathrm{p}_{\mathrm{O}_{2}}$ are responsible for the curvature in the $\log \mathrm{D}_{\mathrm{Co}}^{*}$ vs $\log \mathrm{p}_{\mathrm{O}_{2}}$ plot, we can estimate the corresponding $\mathrm{P}_{\mathrm{O}_{2}}$ dependence of $\mathrm{f} \Delta \mathrm{K}$ on the assumption that diffusion at $\mathrm{p}_{\mathrm{O}_{2}}=1$ atm is entirely due to singly charged unassociated vacancies. We may assume that a $15 \%$ change in $\mathrm{E}$ with $\mathrm{P}_{\mathrm{O}_{2}}$ is easily detected. The curvature in the $\log \mathrm{D}_{\mathrm{Co}}^{*}$.vs $\log \mathrm{p}_{\mathrm{O}_{2}}$ plot then requires that $0.65>$ $\mathrm{E}_{\text {ext }}>0.45$ for the extrinsic or interstitial defects in order for the required $\mathrm{p}_{\mathrm{O}_{2}}$ dependence of $\mathrm{E}$ to go undetected. However, $\mathrm{E}$ ext would be expected to be less than $E_{\text {int }} / 2\left(E_{\text {int }}=0.55\right.$, the value at high $\mathrm{p}_{\mathrm{O}_{2}}$ ) for a dumbbell interstitlal [19], an interstitialcy [20], or an impurityvacancy pair [21] mechanism or near unity for a freely migrating interstitial [22], none of which are within the range of 0.45 to 0.65 that would be consistent with the experimental observations. More qualitative arguments suggest that defect clustering, to the extent suggested by theory for Mno [15], is also inconsistent with the observed $\mathrm{P}_{\mathrm{O}_{2}}$ dependence of $\mathrm{E}$. 


\section{References}

[1] CARTER, R. E. and RICHARDSON, F. D., Trans. AIME 200 (1954) 1244.

[2] FISHER, B. and TANnhauser, D. S., J. Chem. Phys. 44 (1966) 1663.

[3] EROR, N. G. and WAgner, J. B., Jr., J. Phys. Chem. Solids 29 (1968) 1597.

[4] SOCKEL, H. G. and SCHMALzRIED, H.,Ber. Bunsenges. Phys. Chem. $\underline{72}$ (1.968) 745 .

[5] BRANSky, I. and WIMMER, J. M., J. Phys. Chem. Solids 33.(1972) 801.

[6]. FRYT, E., Oxid. Met. 10 (1976) 311.

[7] CHEN, W. K., PEterson, N. L., and REeves, W. T., Phys. Rev. 186 (1969) 887.

[8] CROW, W. T., Ph.D. Thesis, Ohio State University (1969).

[9] DIECKMANN, R., Z. Phys. Chem. Neue Folge 107 (1977) 189.

[10] CHEN, W. K. and JACKSON, R. A., J. Phys. Chem. Solids 30 (1969) 1309.

[11] SHELYKH, A. I., ARTEMOV, K. S., and SHVAIKO-SHVAIKOVSKIT, V. E., Sov. Phys.-Solid State 8 (1966) 706.

[12] HED, A. Z., J. Chem. Phys. 50 (1969) 2935.

[13] MORIN, F., Can MetalZ. Q. 14 (1975) 105.

[14] GVishi, M. and TANnhauser, D. S., J. Phys. Chem. Solids 33 (1972) 893.

[15] CATLOW, C. R. A., FENDER, B., and MUXWORTHY, D. G., J. Phys. (Paris) C7 (1977) 67; Harwe11 Report TP 680 (1978).

[16] CHEN, W. K. and PETERSON, N. L., J. Phys. Chem. Solids 36 (1975) 1097.

[17] PETERSON, N. L., Diffusion in Solids; Recent Developments. Ed. Nowick, A. S. and Burton, J. J. (Academic Press, New York) (1975) p. 115.

[18] MUllen, J. G., Phys. Rev. 121 (1961) 1469.

[19] PETERSON, N. L., J. Nucl. Mater. $\underline{69} \& \underline{70}$ (1978) 3.

[20] PEterson, N. L., BARR, L. W., and Leclatre, A. D., J. Phys. C6 (1973) 2020.

[21] HOWARD, R. E., Phys. Rev. 144 (1966) 650.

[22] BARR, L. W. and LECLAIRE, A. D., Proc. Br. Ceram. Soc. 1 (1964) 109. 
F1g. 1.. - The value of $\mathrm{D}_{\mathrm{Co}}^{*}$ and $\mathrm{f} \Delta \mathrm{K}$ as a function of the oxygen partial pressure for cation self-diffusion in $\mathrm{CoO}$ at $1200^{\circ} \mathrm{C}$. The results of Dieckmann [9] and Chen, Peterson and Reeves [7] are also shown. 


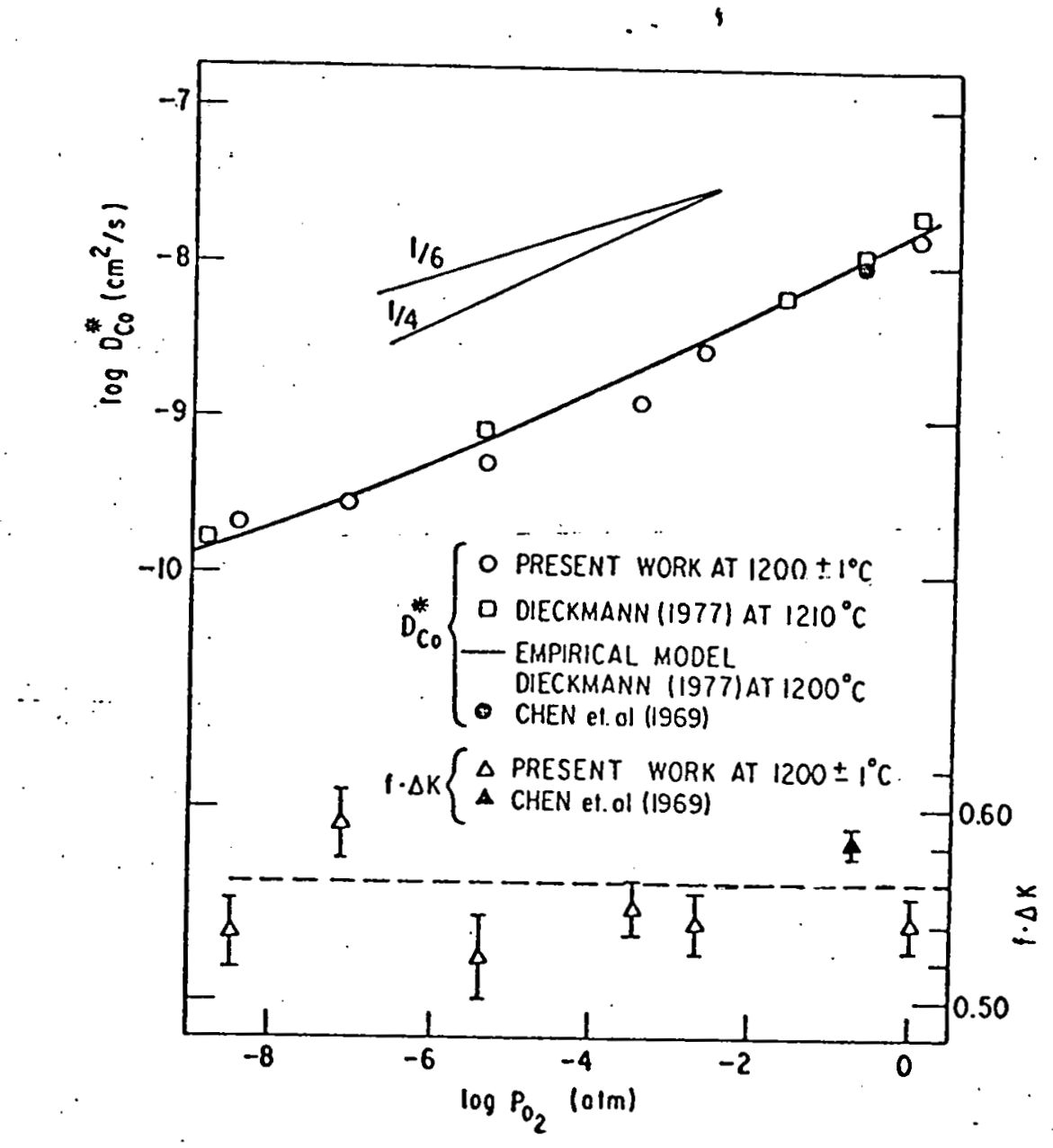

Fig. 1. 